\title{
THE RELATION OF STROKE PATIENT'S CORTISOL LEVEL TO NATIONAL INSTITUTES OF HEALTH STROKE SCALE CORE ON SPONTANEOUS INTRACEREBRAL HEMORRHAGE: AN OBSERVASIONAL STUDY AT RUMAH SAKIT UMUM DAERAH (REGIONAL PUBLIC HOSPITAL) DR. SOETOMO IN SURABAYA
}

\author{
GIBRAN ADITIARA WIBAWA ${ }^{1 *}$, ASRA AL FAUZI ${ }^{2}$ \\ ${ }^{1}$ Department of Faculty of Medicine, Airlangga University, Surabaya, Indonesia. ${ }^{2}$ Departement of Neurosurgery, Adhyaksa General
} Hospital, Jakarta, Indonesia. Email: gibranwibawa@yahoo.com

Received: 10 July 2018, Revised and Accepted: 07 December 2018

ABSTRACT

Objective: The objective of the study was to find out differences in the cortisol level characteristics and National Institutes of Health Stroke Scale (NIHSS) score in the $1^{\text {st }}$ and $7^{\text {th }}$ days on patients treated at Dr. Soetomo Regional Hospital; thus, it can be the right education for stroke patients.

Methods: A prospective observational study was carried out against stroke patients treated in the neurosurgery department on September 2016March 2017. Evaluation was done to all patients treated at the neurosurgery department. The evaluation process began with basal hormones within the first $24 \mathrm{~h}$ and taken at 6:00 and repeated on the $7^{\text {th }}$ day to surviving patients. Of all the data obtained, the category scale data are presented by its frequency distribution, while numerical scale data are presented by its descriptive value (average and standard deviation).

Results: Of the 17 patients surviving until the $7^{\text {th }}$ day, there is a decrease at the average cortisol level on the $1^{\text {st }}$ day when compared to the average cortisol level on the $7^{\text {th }}$ day with a mean value of $39.67-36.57$ and so is the highest cortisol level; it decreases from the $1^{\text {st }}$ day of 61.45 to the $7^{\text {th }}$ day of 56.70. Meanwhile, in the NIHSS score value, the decrease in score only occurs in the average value on the $1^{\text {st }}$ and $7^{\text {th }}$ days from an average of 22.82 into 21.41, whereas minimum and maximum scores do not change. With the test result, the cortisol level characteristic gets a score of p<0.05; thus, there is a significant difference.

Conclusion: Of the result of observation already carried out on stroke patients treated at Dr. Soetomo Regional Hospital, treatment and education levels for patients who have a risk of stroke factor are very important.

Keywords: Stroke, Hemorrhage, National Institutes of Health Stroke Scale, Cortisol

(C) 2019 The Authors. Published by Innovare Academic Sciences Pvt Ltd. This is an open access article under the CC BY license (http://creativecommons. org/licenses/by/4. 0/) DOI: http://dx.doi.org/10.22159/ajpcr.2019.v12i1.28405

\section{INTRODUCTION}

Increased stroke patient is one interesting topic that draws the attention of researchers [1]. One type of stroke commonly found is intracerebral hemorrhage (ICH). According to Fathima et al. [2] of $70 \%$ incidence of ischemic stroke, $20 \%$ of cases are ICH. Thus, this case gains much concern, although there are a lot of factors causing a stroke [3].

In the past 2 years, the number of hemorrhage stroke cases at Dr. Soetomo Regional Public Hospital (Rumah Sakit Umum Daerah, RSUD) had significantly increased, which made it a particular concern.

For the past 10 years, the knowledge development of spontaneous ICH (SICH) increasingly changed [4-6], for example, a radiology technique for diagnosing in vivo from ICH was found. The ICH occurs when the blood vessel in the brain parenchyma is ruptured. SICH can also happen as the result of a complication of previous lesions, such as vascular malformation or tumor, which is categorized as secondary SICH. When ICH occurred, blood vessels in the brain parenchyma ruptured. This causes an acute illness and gives effect to stroke patients where their cortisol levels are increased. Cortisol levels give an indication of the disease severity and its recovery phases. Cortisol may also be referred to as a short-term prognostic sign from the functional outcome and mortality. The same thing can be occurred in stroke patients who have an experience where cortisol levels increased in 7 days after the occurrence of stroke.

Reffering to Barugh et al. [7] the increased cortisol after related with subordination, disability, and mortality. However, there is insufficient evidence to draw conclusion that this relation does not depend on the severity of stroke.

One of the commonly used measuring tools to assess severity degree of a stroke is National Institutes of Health Stroke Scale (NIHSS). NIHSS and NIHSS modified have superiority in assessing the neurological deficit compared to other measuring tools $[8,9]$. By understanding the relationship between the increased level of cortisol and NIHSS scorer to acute stroke patients on the first 7 day, then, the pattern of handling stroke sufferers can be optimal. Also, a predict recovery of ambulation and upper limb function after 6-month stroke by age and NHISS models as [10].

\section{RELATED WORK}

Until now, the topic of handling stroke patients has become very interesting. Hence, many researchers want to improve performance with a variety of methods [11-14]. SICH is a multi-factorial and etiological disease, and it is the second most occurring kind of stroke after ischemic stroke with the percentage of $10-20 \%$ of all kinds of stroke cases. According to Ikram et al. [15], hypertension is the dominant factor that affects the ICH occurrence. It corresponds to research in Japan, which has been issued by Aguilar and Freeman [16].

The understanding of axis hypothalamic-pituitary-adrenal activation during acute condition, which causes the increasing of cortisol serum concentration, is often connected to the severity level of diseases and prognosis. If a patient successfully passes the acute phase but experiences an elongation in a recovery process, a prolonged critical 
period may occur [17]. The case of increasing cortisol level on the first 7 days after the stroke is very high.

Cortisol can be used as a prognostic factor of short-term functional ability and death to a patient in China who suffers from an acute ischemic stroke. Studies on the relationship between neuroendocrine change and SICH are not strong enough and still cause conflict [18]. Some studies state that there is a change of the cortisol level in a stroke patient but not specifically for ICH [19].

The increase of the cortisol level is related to symptoms of confusion and poor output of a post-stroke patient. Hypercortisolism is also related to an initial cognitive dysfunction after the occurrence of ischemic stroke. The fluctuative change of the cortisol level affects the increase of death rate after the ischemic stroke [20]. During the acute ischemic stroke, a stress response may occur, and catecholamines increase is proven to be related to the stroke severity level and final output [21]. Death on an acute stroke patient is related to the increase of cortisol serum level while S-Cortisol is related to the stroke severity level [22]

\section{RESEARCH METHOD}

This research is conducted using an analytic observation method while the samples used are all ICH patients of RSUD Dr. Soetomo that have fulfilled inclusion criteria.

17 patients ( 9 females and 8 males, Table 1 ) who were treated by a team of neurosurgeons at RSUD Dr. Soetomo from August 2016 to June 2017 had fulfilled an inclusion and exclusion criteria to form a study group in this research. The sample size is taken using a correlation formula:

$$
\mathrm{n}=\{(\mathrm{Z} \alpha+\mathrm{Z} \beta) /(0,5 \ln [(1+\mathrm{r}) /(1-\mathrm{r})])\}^{2}+3
$$

Then,

$$
\begin{aligned}
& \alpha=0.05 \rightarrow Z_{\alpha}=1.96 \\
& \beta=0.20 \rightarrow Z_{\beta}=0.84
\end{aligned}
$$

The exclusion criteria are of age $<17$ years old and no $>60$ years old, having an endocrine disorder, sustaining an extracranial injury, experiencing hemorrhage caused by aneurysm/avm, and having a metabolic disorder. An initial computed tomography scan examination is applied to the patients to diagnose the ICH. The volume measurement is made based on the $\mathrm{ABC} / 2$ technique, and it is possible that the intraventricular hemorrhage is scored using the Graeb scheme. Following flowchart is shown in Fig. 1.

Hypothesis:

The levels of cortisol on day 1 and 7 are different

Sig. $>0.05=\mathrm{H}_{0}$ accepted,

Sig. $<0.05=\mathrm{H}_{0}$ is rejected

The NIHSS score of days 1 and 7 is different

Sig. $>0.05=\mathrm{H}_{0}$ accepted,

Sig. $<0.05=\mathrm{H}_{0}$ is rejected

Relationship between cortisol levels day 1 with mortality.

Evaluation of basal hormone is applied to all patients within the first $24 \mathrm{~h}$ of being hospitalized. A blood sample is taken at $6.00 \mathrm{a}$.m. on the following day and is repeated on the $7^{\text {th }}$ day only for the patients who survive. The normal level of cortisol hormone is $5-25 \mathrm{mgm} \mathrm{dl} / 1$.

The clinical condition of the patients is measured using NIHSS. The measurement is conducted when the patients come and on the $7^{\text {th }}$ day. The NIHSS score has been directly evaluated by researchers. All data have been tabulated and analyzed.

\section{RESULTS}

This research is conducted for 6 months by collecting the medical record data of the patients from the period of September 2016 to March 2017 at RSUD Dr. Soetomo. The collected data are the data of the acute ICH stroke patients. The population collected is 17 patients. The data are divided into the inclusion and exclusion data, as many as 17 patients and 9 patients with characteristics as presented the Table 1.

Table 1 shows the total and percentage of research samples based on age and gender between female and male from the period of September 2016 to March 2017 at RSUD Dr. Soetomo.

The cortisol level of each patient is examined on the $1^{\text {st }}$ and the $7^{\text {th }}$ days. Table 2 shows the cortisol examination result on the $1^{\text {st }}$ and the $7^{\text {th }}$ days.

From the data above, it can be seen that the average value of cortisol on the $1^{\text {st }}$ day is quite high, which is 39.67 from 17 samples. On the other hand, on the $7^{\text {th }}$ day, it can be seen that the cortisol level decreases to the average of 36.57 and the maximum level acquired by the patients also decreases. The maximum value on the $1^{\text {st }}$ day is 61.45 with $\mathrm{p}<0.05$. It means that there is a significant difference on the cortisol level of day 1 and the cortisol level of day 7.

After acquiring the cortisol level of each patient from day 1 to day 7, the next thing to do is to test the different NIHSS score from each patient from day 1 to day 7 . The examination result can be seen from Table 3 .

The NIHSS score of the 17 patients has total value of 22.82 with the $p$ (paired t-test) level of 0.165 . The value has slightly decreased on the $7^{\text {th }}$ day to 21.41 . However, there is no change in the maximum value of NIHSS, which is 36 . There is also no change in the minimum value, which is 5 in the NIHSS score.

On the other hand, the result of different characteristic examination between the NIHSS score on the $1^{\text {st }}$ day and the $7^{\text {th }}$ day is $p>0.05$, which means the characteristic of NIHSS score on the $1^{\text {st }}$ day with the cortisol level on the $7^{\text {th }}$ day is the same. Table 4 shows the change in NIHSS score from the observed patient.

Regarding the data above, most patients did not experience changes NIHSS score day- 1 and day-7. There was one patient who

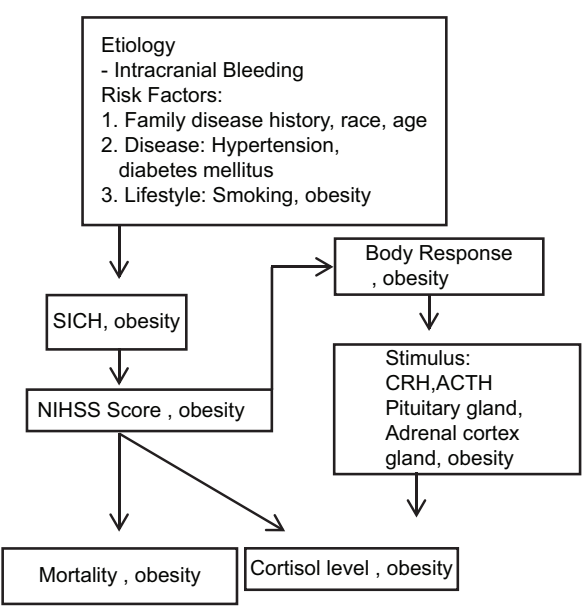

Fig. 1: Flowchart

Table 1: Characteristics of patients

\begin{tabular}{lll}
\hline Character & \multicolumn{2}{l}{ Characteristics } \\
\cline { 2 - 3 } & & Percentage \\
\hline Age $(\mathrm{n}=17)$ & Mean \pm SD & $51.64 \pm 6.56$ \\
& Minimum & 43 \\
\multirow{2}{*}{ Gender $(\mathrm{n}=17)$} & Maximum & 60 \\
& Male & 47.05 \\
& Female & 52.95 \\
\hline
\end{tabular}


Table 2: Test of different levels of cortisol on day 1 until day 7

\begin{tabular}{llllll}
\hline Take time & $\mathbf{n}$ & Mean \pm SD & Minimum & Maximum & p (paired t-test) Sig. (2-tailed) \\
\hline Day 1 & 17 & $39.67 \pm 16.16$ & 5.01 & 61.45 \\
Day 7 & 17 & $36.57 \pm 13.58$ & 6.70 & 56.70 \\
\hline
\end{tabular}

Table 3: Test of different NIHSS score day 1 and day 7

\begin{tabular}{lllll}
\hline Day & $\mathbf{n}$ & Mean \pm SD & Minimum & Maximum \\
\hline $1^{\text {st }}$ & 17 & $22.82 \pm 9.44$ & 5 & 36 \\
$7^{\text {th }}$ & 17 & $21.41 \pm 9.92$ & 5 & 0.165 \\
\hline
\end{tabular}

NIHSS: National Institutes of Health Stroke Scale

Table 4: NHISS score data change day 1 and day 7

\begin{tabular}{|c|c|c|c|c|c|}
\hline \multirow[t]{2}{*}{ NIHSS day $1^{\text {st }}$} & \multicolumn{5}{|c|}{ NIHSS day $7^{\text {th }}$} \\
\hline & Light (\%) & Medium (\%) & Weight (\%) & Very heavy (\%) & $? ? ?$ \\
\hline Light & $2(11.76)$ & - & - & - & $2(11.76)$ \\
\hline Medium & - & $2(11.76)$ & - & - & $2(11.7)$ \\
\hline Weight & - & $1(5.88)$ & $5(29.4)$ & - & $6(35.29)$ \\
\hline Very heavy & - & $1(5.88)$ & - & $6(35.29)$ & $7(41.17)$ \\
\hline Total & 2 & 4 & 5 & 6 & $17(100)$ \\
\hline
\end{tabular}

NIHSS: National Institutes of Health Stroke Scale

Table 5: Correlation of the cortisol levels and NIHSS score (Pearson test)

\begin{tabular}{lllll}
\hline & K-1 & K-7 & N-1 & N-7 \\
\hline K-1 & & & & \\
$\quad$ Pearson correlation & - & 0.96 & 0.717 & 0.619 \\
$\quad$ Sig. 2 Tailed & - & 0.00 & 0.01 & 0.01 \\
K-7 & & & & \\
$\quad$ Pearson correlation & 0.96 & - & 0.721 & 0.669 \\
$\quad$ Sig. 2 Tailed & 0.00 & - & 0.01 & 0.03 \\
N-1 & & & & \\
$\quad$ Pearson correlation & 0.717 & 0.721 & - & 0.916 \\
$\quad$ Sig. 2 Tailed & 0.01 & 0.01 & - & 0.00 \\
N-7 & & & & - \\
$\quad$ Pearson correlation & 0.619 & 0.669 & 0.916 & - \\
$\quad$ Sig. 2 Tailed & 0.01 & 0.03 & 0.00 & - \\
\hline
\end{tabular}

NIHSS: National Institutes of Health Stroke Scale

experienced improvement from the weight group to moderate, and one patient experienced improvement from very heavy group to moderate.

The NIHSS score of the 17 patients has the total value of 22.82 with the $\mathrm{p}$ (paired t-test) level of 0.165 . The value has slightly decreased on the $7^{\text {th }}$ day to 21.41 . However, there is no change in the maximum value of NIHSS, which is 36 . There is also no change in the minimum value, which is 5 in the NIHSS score.

On the other hand, the result of different characteristic examination between the NIHSS score on the $1^{\text {st }}$ day and the $7^{\text {th }}$ day is $p>0.05$, which means the characteristic of NIHSS score on the $1^{\text {st }}$ day with the cortisol level on the $7^{\text {th }}$ day is the same. The subsequent relationship of cortisol levels to NIHSS score on day 1 and day 7 is as follows as presented in Table 5.

Seen on several lines above, the significance can be determined by Sig line (2-tailed). If the value is Sig ( 2 -tailed) $<0.05$.

The most of patients did not experience any changes of NIHSS Score on day 1 and day 7, but there was one patient who experienced improvement from the weight group to moderate and one patient experienced improvement from very heavy group to moderate. It is likely that stroke patients with greater initial symptom severity tends to have an unfavorable prognosis while the difference of cortisol levels with the output number using independent test is as follows as presented in Table 6.

The results of the data above show that there is no difference among the average value of cortisol the $1^{\text {st }}$ day in the group of patients died and alive ( $p>0.05$ ), the average $7^{\text {th }}$ day cortisol in the group died and alive $(p>0.05)$, and the mean NIHSS score day to- 1 in the group of patients died and alive ( $p>0.05)$. However, there was a difference between the mean $7^{\text {th }}$ day NIHSS score in the death and live patient group $(\mathrm{p}<0.05)$. After obtaining a cortisol level with NIHSS score, next, correlation of NIHSS score to mortality on day 1 and day 7 by contingency coefficient (Cramer's V) method is presented in Tables 7 and 8.

Based on the data of correlation test of NIHSS day-1 with mortality using contingency coefficient (Cramer's V) obtained contingency coefficient of 0.556 and significance level of 0.055 , which means there is no significant relationship between NIHSS score day 1 with mortality. As for the $7^{\text {th }}$ day of contingency coefficient of 0.634 and significance level of 0.010 , it means that there is a significant correlation between the score of NIHSS day-7 and mortality. NIHSS has a high predictive ability to output in stroke patients at different times after the onset of symptoms.

\section{CONCLUSION}

SICH is one of the processes, which is caused by the pathological disorder previously experienced by a patient. The variable of cortisol level on the day 1 , cortisol level on day 7 , NIHSS score on the day 1 , NIHSS on the day 7 , and mortality correlates with one another with various strength. However, if each variable of the cortisol level and NIHSS score is correlated to the mortality, only NIHSS score on the day 7 and mortality is statistically significant. The high death rate in this study is due to the high infection cases at RSUD Dr. Soetomo. The deaths of all deceased patients are caused by lung infection with various microbiological culture results. 
Table 6: Difference cortisol level with output number

\begin{tabular}{|c|c|c|c|c|c|c|}
\hline Var. & Outcome & $\mathbf{n}$ & Mean \pm SD & Minimum & Maximum & p (2 tailed) \\
\hline \multirow[t]{2}{*}{$\mathrm{K}-1$} & Life & 4 & $32.85 \pm 18.25$ & 8.40 & 50.80 & Sig. 0.351 \\
\hline & Die & 13 & $41.77 \pm 15.64$ & 5.01 & 61.45 & \\
\hline \multirow[t]{2}{*}{ K-7 } & Life & 4 & $28.78 \pm 13.35$ & 12.54 & 45.20 & Sig. 0.199 \\
\hline & Die & 13 & $38.97 \pm 13.22$ & 6.70 & 56.70 & \\
\hline \multirow[t]{2}{*}{$\mathrm{N}-1$} & Life & 4 & $15 \pm 11.57$ & 5 & 26 & Sig. 0.055 \\
\hline & Die & 13 & $25.23 \pm 7.67$ & 13 & 36 & \\
\hline $\mathrm{N}-7$ & Life & 4 & $9 \pm 4.61$ & 5 & 13 & Sig. 0.001 \\
\hline
\end{tabular}

NIHSS: National Institutes of Health Stroke Scale

Table 7: Correlation of NIHSS score and mortality day

\begin{tabular}{llll}
\hline NIHSS - day 1 & Outcome & $\begin{array}{l}\text { Coefficient Cramer's } \\
\text { V=0.669, p=0.055 (\%) }\end{array}$ \\
\cline { 2 - 3 } & Life (\%) & Die (\%) & \\
\hline Light & $2(100)$ & $0(0)$ & $2(100)$ \\
Medium & $0(0)$ & $2(100)$ & $2(100)$ \\
Weight & $1(16.6)$ & $5(83.4)$ & $6(100)$ \\
Very heavy & $1(14.3)$ & $6(85.7)$ & $7(100)$ \\
E & $4(23.5)$ & $13(76.5)$ & $17(100)$ \\
\hline
\end{tabular}

NIHSS: National Institutes of Health Stroke Scale

Table 8: Correlation of NIHSS score and mortality day 7

\begin{tabular}{llll}
\hline NIHSS - day 7 & Outcome & $\begin{array}{l}\text { Coefficient Cramer's } \\
\text { V=0.820, p=0.010 (\%) }\end{array}$ \\
\cline { 2 - 3 } & Life (\%) & Die (\%) & \\
\hline Light & $2(100)$ & $0(0)$ & $2(100)$ \\
Medium & $2(50)$ & $2(50)$ & $4(100)$ \\
Weight & $0(0)$ & $5(100)$ & $5(100)$ \\
Very heavy & $0(0)$ & $6(100)$ & $6(100)$ \\
E & $4(23.5)$ & $13(76.5)$ & $17(100)$ \\
\hline
\end{tabular}

NIHSS: National Institutes of Health Stroke Scale

\section{AUTHOR(S) CONTRIBUTION}

Both the authors contributed equally to this manuscript.

\section{CONFLICTS OF INTEREST}

The author(s) declare(s) that there are no conflicts of interest regarding the publication of this article.

\section{REFERENCES}

1. Mathew E, Chandrika C, Karanath PM, Srinivasa R. A prospective observational study on prescribing trends and adverse drug reactions in stroke patients. Int J Pharm Pharm Sci 2017;9:25.

2. Fathima M, Najeeb S, Fatima S, Khalid SM, Nikhat SR, Rao RC. A prospective observational study on risk factors and management of stroke at a tertiary care teaching hospital. Int J Pharm Pharm Sci 2018;10:45.

3. Ahmed SJ, Masood AR, Sumana S, Ghori KA, Ansari JA, Khan M. Stroke outcomes in non-diabetic, denovo diabetic and diabetic Indian patients measured by modified rankin scale: An observational study. Int J Pharm Pharm Sci 2017;9:94.

4. Elkholy SF, Khalil ME, Elbasmi AA, Mahmoud BE, Edrees M. Diffusion tensor magnetic resonance imaging in assessment of prognostic outcome of stroke patients. Egypt J Radiol Nucl Med 2015;46:707-13
5. YamadaT, Natori Y. Acute blood-pressure management and prognostic factors in patients with intracerebral hemorrhage. Interdiscip Neurosurg 2017;10:91-5

6. Bernotas G, Simaitis K, Bunevičius A, Tamašauskas A. Safety and efficacy of stereotactic aspiration with fibrinolysis for deep-seated spontaneous intracerebral hemorrhages: A single-center experience. Medicina (Kaunas) 2017;53:303-9.

7. Barugh AJ, Gray P, Shenkin SD, MacLullich AM, Mead GE. Cortisol levels and the severity and outcomes of acute stroke: A systematic review. J Neurol 2014;261:533-45.

8. Harrison JK, McArthur KS, Quinn TJ. Assessment scales in stroke: Clinimetric and clinical considerations. Clin Interv Aging 2013;8:201-11.

9. Meyer BC, Lyden PD. The modified national institutes of health stroke scale: Its time has come. Int J Stroke 2009;4:267-73.

10. Kwah LK, Harvey LA, Diong J, Herbert RD. Models containing age and NIHSS predict recovery of ambulation and upper limb function six months after stroke: An observational study. J Physiother 2013;59:189-97.

11. Koge J, Matsumoto S, Nakahara I, Ishii A, Hatano T, Sadamasa N, et al. Improving treatment times for patients with in-hospital stroke using a standardized protocol. J Neurol Sci 2017;381:68-73.

12. Abdeldayem EH, Osman AM, Roushdy TM. Relative fractional anisotropy value using DTI: Can it help as a prognostic tool in anticipating the recovery of stroke patients? Egypt J Radiol Nucl Med 2017;48:1019-25

13. Chang JJ, Khorchid Y, Kerro A, Burgess LG, Goyal N, Alexandrov AW, et al. Sulfonylurea drug pretreatment and functional outcome in diabetic patients with acute intracerebral hemorrhage. J Neurol Sci 2017;381:182-7.

14. Spurthi T, Rani KR, Navya Y, Swathi D, Kumar PR. Acute post complications in stroke patients visiting a tertiary teaching hospital. Int J Pharm Pharm Sci 2018;10:94.

15. Ikram MA, Wieberdink RG, Koudstaal PJ. International epidemiology of intracerebral hemorrhage. Curr Atheroscler Rep 2012;14:300-6.

16. Aguilar MI, Freeman WD. Spontaneous intracerebral hemorrhage. Semin Neurol 2010;30:555-64.

17. Dromerick AW, Edwardson MA, Edwards DF, Giannetti ML, Barth J, Brady KP, et al. Critical periods after stroke study: Translating animal stroke recovery experiments into a clinical trial. Front Hum Neurosci 2015;9:231.

18. Chaker L, Baumgartner C, den Elzen WP, Ikram MA, Blum MR, Collet $\mathrm{TH}$, et al. Subclinical hypothyroidism and the risk of stroke events and fatal stroke: An individual participant data analysis. J Clin Endocrinol Metab 2015;100:2181-91.

19. El Husseini N, Laskowitz DT. The role of neuroendocrine pathways in prognosis after stroke. Expert Rev Neurother 2014;14:217-32.

20. Marklund N, Peltonen M, Nilsson TK, Olsson T. Low and high circulating cortisol levels predict mortality and cognitive dysfunction early after stroke. J Intern Med 2004;256:15-21.

21. Back C, Thiesen KL, Skovgaard K, Edvinsson L, Jensen LT, Larsen VA, et al. RAAS and stress markers in acute ischemic stroke: Preliminary findings. Acta Neurol Scand 2015;131:132-9.

22. Christensen H, Boysen G, Johannesen HH. Serum-cortisol reflects severity and mortality in acute stroke. J Neurol Sci 2004;217:175-80. 